\title{
Safety and Short-Term Toxicity of a Novel Cationic Lipid Formulation for Human Gene Therapy
}

\author{
HONG SAN, ${ }^{1}$ ZHI-YONG YANG,${ }^{1,2,5}$ VINCENT J. POMPILI, ${ }^{1}$ MICHELE L. JAFFE, ${ }^{1,2,5}$ \\ GREGORY E. PLAUTZ, ${ }^{3}$ LING XU,${ }^{1}$ JIIN H. FELGNER, ${ }^{6}$ CARL J. WHEELER, ${ }^{6}$ PHILIP L. FELGNER, ${ }^{6}$ \\ XIANG GAO,${ }^{7}$ LEAF HUANG,${ }^{7}$ DAVID GORDON,${ }^{4}$ GARY J. NABEL,${ }^{1,2,5}$ and \\ ELIZABETH G. NABEL ${ }^{1}$
}

\begin{abstract}
Among the potential nonviral vectors for human gene therapy are DNA-liposome complexes. In a recent clinical study, this delivery system has been utilized. In this report, a novel cationic lipid, dimyristyloxypropyl3-dimethyl-hydroxyethyl ammonium (DMRIE), has been substituted into the DNA-liposome complex with dioleoyl phosphatidylethanolamine (DOPE), which both improves transfection efficiencies and allows increased doses of DNA to be delivered in vivo. The safety and toxicity of this DNA-liposome complex has been evaluated in two species, mice and pigs. The efficacy of DMRIE/DOPE in inducing an antitumor response in mice after transfer of a foreign MHC has been confirmed. No abnormalities were detected after administration of up to 1,000-fold higher concentrations of DNA and lipid than could be tolerated in vivo previously. Examination of serum biochemical enzymes, pathologic examination of tissue, and analysis of cardiac function in mice and pigs revealed no toxicities related to this treatment. This improved cationic lipid formulation is well-tolerated in vivo and could therefore allow higher dose administration and potentially greater efficiency of gene transfer for gene therapy.
\end{abstract}

\section{OVERVIEW SUMMARY}

\begin{abstract}
A Ithough several viral vectors have been widely applied to the treatment of human disease, the development of nonviral vectors is still in their infancy. In this report, a novel cationic lipid, DMRIE/DOPE, has been incorporated into the DNA-liposome formulation that improves transfection efficiencies and allows up to 1,000-fold higher concentrations of DNA to be administered in vivo. In this paper, the safety and toxicity of this formulation is described in two species, mice and pigs, suggesting that it may prove useful for human gene therapy.
\end{abstract}

\section{INTRODUCTION}

Departments of ${ }^{1}$ Internal Medicine and ${ }^{2}$ Biological Chemistry, ${ }^{3}$ Pediatrics, and ${ }^{4}$ Pathology, and ${ }^{5}$ Howard Hughes Medical Institute, University of Michigan Medical Center, Ann Arbor, MI 48 109-0650.

${ }^{6}$ Vical, Inc., San Diego, CA 92121

${ }^{7}$ University of Pittsburgh, Pittsburgh, PA I5261. 
DNA-liposome complexes and to modify biologic effects in vivo has been established (E.G. Nabel et al., 1992b, 1993a,b; Plautz et al., 1993), the ability to transduce larger numbers of cells could greatly expand its utility.

There are several potential advantages of DNA-liposome complexes as a nonviral delivery system. Because the DNA is not directly derived from a replication competent virus, its expression is limited. It is unlikely to integrate or propagate in animal cells, thus minimizing concerns related to public health and vector safety. In addition, cationic lipids have been welltolerated in vivo (E.G. Nabel et al., 1992a; Stewart et al., 1992). Based on a variety of animal models (E.G. Nabel et al., 1992a,b, 1993a,b; Stewart et al., 1992) and clinical studies (G.J. Nabel et al., 1992a, 1993) in progress, applications of this technology are likely to expand in the future. Finally, the ability to deliver recombinant genes using catheter-based delivery has further allowed for site-specific gene expression in vivo.

Despite the advantages of this technique, some limitations of the present technology remain. Among them has been the relatively low concentration of DNA-liposome complexes that are employed. In previous studies, higher absolute concentrations of DNA-liposome complexes led to aggregation and toxicity following intravenous injection in mice in vivo (Stewart et al., 1992). A new formulation (Felgner et al., 1993) is characterized in this report. This DNA-liposome formulation displays a modestly higher transfection efficiency in vitro. More importantly, it does not show toxicity at higher absolute concentrations of DNA and lipid. In this report, we characterize the in vivo toxicities of this formulation in mice and pigs. We find minimal toxicity at lipid and DNA concentrations up to 1000fold higher than those used previously. Based on these results, this DNA-liposome formulation may be an appropriate delivery vehicle for gene transfer in humans.

\section{MATERIALS AND METHODS}

\section{Plasmids and transfections}

A plasmid containing the HLA-B7 gene (G.J. Nabel et al., 1992a, 1993) under the control of the Rous sarcoma virus long terminal repeat (RSV-LTR) was used for transfection of different primary and transformed cell lines and for in vivo toxicity analysis. This plasmid was approved for use in our previous human clinical protocol (G.J. Nabel et al., 1992a, 1993). Cells were transfected with dimethylaminoethane-carbamoyl cholesterol (DC-Chol)/dioleoyl phosphatidylethanolamine (DOPE) in an optimal concentration (15 nmol DC-Chol/DOPE; $1 \mu \mathrm{g}$ DNA in $0.7 \mathrm{ml}$ ) as previously described (Gao and Huang, 1991; Stewart et al., 1992). The newer DNA-liposome formulation was prepared by incubation of DNA $(5 \mu \mathrm{g})$ and dimyristyloxypropyl-3-dimethyl-hydroxyethyl ammonium (DMRIE)/DOPE $(15 \mathrm{nmol})$ in a final volume of $1 \mathrm{ml}$ in lactated Ringer's solution for in vitro transfections.

\section{Animal studies}

Adult female mice (strain BALB/c) and domestic pigs were used for all in vivo experiments. Experiments in mice were performed to evaluate escalating doses of DNA and liposomes injected intravenously. Intravenous injections were carried out via the tail vein using a 21 -gauge needle. In mice, for intravenous injections, DNA $(0.5-50 \mu \mathrm{g})$ and DMRIE/DOPE (1.5$150 \mathrm{nmol}$ ) were mixed in a final volume of $0.1 \mathrm{ml}$ immediately prior to injection. Blood was collected from the tail vein before intravenous injection of the DNA-liposomes and 10 days later. At about 2 weeks following injection, liver, kidney, lung, heart, and brain were removed for histologic analysis and extracted for polymerase chain reaction (PCR) DNA amplification using primers and conditions described previously (G.J. Nabel et al., 1993) in one group of mice $(n=5)$. In a second group, injections were repeated at 2-week intervals for a total of three times. Blood was collected before the first injections and 6 weeks later, at which time organs were removed and analyzed by histology and PCR.

Additional toxicity studies were performed in 12 pigs to evaluate the local and systemic effects of three doses of DNA and liposomes when delivered by a catheter to a local peripheral artery segment. Intra-arterial gene transfer was performed using a double balloon catheter (USCI, Bard, Inc., Billerica, MA) with methods previously described (Nabel et al., 1990). In these experiments, the plasmid containing the HLA-B7 gene was mixed with DMRIE/DOPE in three concentrations: HLA-B7 DNA $0.5 \mu \mathrm{g}$ and DMRIE/DOPE $1.5 \mathrm{nmol}$ (2 pigs); HLA-B7 DNA $5 \mu \mathrm{g}$ and DMRIE/DOPE $15 \mathrm{nmol}$ (4 pigs); and HLA-B7 DNA $50 \mu \mathrm{g}$ and DMRIE/DOPE $150 \mathrm{nmol}$ (6 pigs). The animals were sacrificed at 17-21 days. The following evaluations were performed. Tissue analysis for PCR and histology were done 17-21 days following gene transfer to determine the effectiveness of gene transfer and the effects of gene expression on tissues. Serum chemistries were measured before gene transfer and 17 days later to examine effects of DNA and DMRIE/DOPE liposomes on liver, renal, and cardiac function.

The PCR reactions were performed as previously described (G.J. Nabel et al., 1993) with a 2-min annealing and extension at $72^{\circ} \mathrm{C}$ and $1 \mathrm{~min}$ of dissociation of $94^{\circ} \mathrm{C}$. Plasmid DNA was used as positive control ( $1 \mathrm{ng}$ ). The sensitivity of detection has been estimated to be between 1 copy per $10^{3}-10^{5}$ genomes (Stewart et al., 1929). Serum samples were stored frozen at $-20^{\circ} \mathrm{C}$ for measurement of tissue-specific enzymes and routine biochemical parameters.

\section{Studies of cardiac toxicity}

The effects of intravenous DNA-liposome complexes on cardiac tissue were assessed by measurement of total creatine phosphokinase (CPK), CPK isoenzymes, and electrocardiography (EKG) on 15 mice prior to and following DNA-liposome injection. Total CPK values were determined prior to injection. Mice received HLA-B7 DNA-liposome conjugates prepared as described above $(0.1 \mathrm{cc})$ injected into the tail vein. CPK measurements were made on serum samples obtained 16 hr after injection. Control mice were injected with $0.1 \mathrm{cc}$ of saline, and total CPK was measured at $16 \mathrm{hr}$.

As an independent parameter to evaluate cardiac function, EKG measurements were performed prior to DNA-liposome complex or saline injection, during injection, and 1 and $5 \mathrm{~min}$ following injection. The mice were anesthetized and surface lead electrodes were attached to the four limbs using alcohol. 
Surface lead I or II was monitored at a chart speed of 50 $\mathrm{mm} / \mathrm{sec}$. After the baseline EKG was obtained, continuous measurements were made during injection.

\section{Direct arterial gene transfer in vivo}

Direct arterial transfection was performed in 12 pigs using methods as previously described in peripheral iliofemoral arteries using a catheter (E.G. Nabel et al., 1990, 1992b). In this study, the expression of the human recombinant gene was analyzed up to 17 days following direct gene transfer in pigs. Genomic DNA was prepared from transfected and nontransfected arteries, ovary or testes, heart, lung, liver, spleen, kidney, and skeletal muscle by standard proteinase $\mathrm{K}$ digestion and phenol and chloroform extraction conditions. Oligonucleotide primers were synthesized to generate the 525-bp fragment as described above.

\section{Analysis of organ toxicity}

Organ specimens, including transfected and nontransfected artery, ovary or testes, brain, heart, lung, liver, spleen, kidney, and muscle were obtained when the animals were sacrificed, fixed in formalin, embedded in paraffin, and stained in hematoxylin and eosin. Representative sections were examined by an experienced pathologist (D.G.) in a blinded fashion.

Serum from mice or pigs was obtained prior to sacrifice, frozen at $-20^{\circ} \mathrm{C}$, and biochemical analyses were performed (Roche Biomedical Laboratories, Dublin, $\mathrm{OH}$ ). Mean values and standard errors of the mean (SEM) prior to and following gene transfer were compared using a two-tailed paired $t$-test. Results were considered statistically significant if $p \leqslant 0.05$.

\section{RESULTS}

\section{Comparison of transfection efficiencies of DMRIE/DOPE and DC-Chol/DOPE in vitro}

To compare the efficacy of DMRIE/DOPE to the DC-Chol/ DOPE, a variety of cell lines were transfected in vitro. Among the cell lines, the DMRIE/DOPE formulation showed an improved transfection efficiency ranging from two- to seven-fold, depending on the lines that were examined (Fig. 1). In general, the relative improvement with DMRIE/DOPE was most effective in cell lines that were difficult to transfect with both cationic lipids, e.g., MCA 205 fibrosarcoma. It is also important to note that a higher concentration of plasmid DNA was used with DMRIE/DOPE $(5 \mu \mathrm{g})$ than DC-Chol/DOPE ( $1 \mu \mathrm{g})$ because this higher concentration of plasmid was toxic to cells in vitro with DC-Chol/DOPE (Stewart et al., 1992). Thus, DMRIE/DOPE is not necessarily more potent than DC-Chol/ DOPE, but its relative lack of toxicity allows larger quantities of DNA to be used in vitro and in vivo.

In Fig. 2, an example is provided regarding the potential for improved therapy with this new liposome formulation. A subclone of MCA 205 , a murine fibrosarcoma $\left(\mathrm{H}-2 \mathrm{~K}^{\mathrm{b}}\right)$, was poorly transfected by DC-Chol/DOPE liposome. Using the DMRIE/

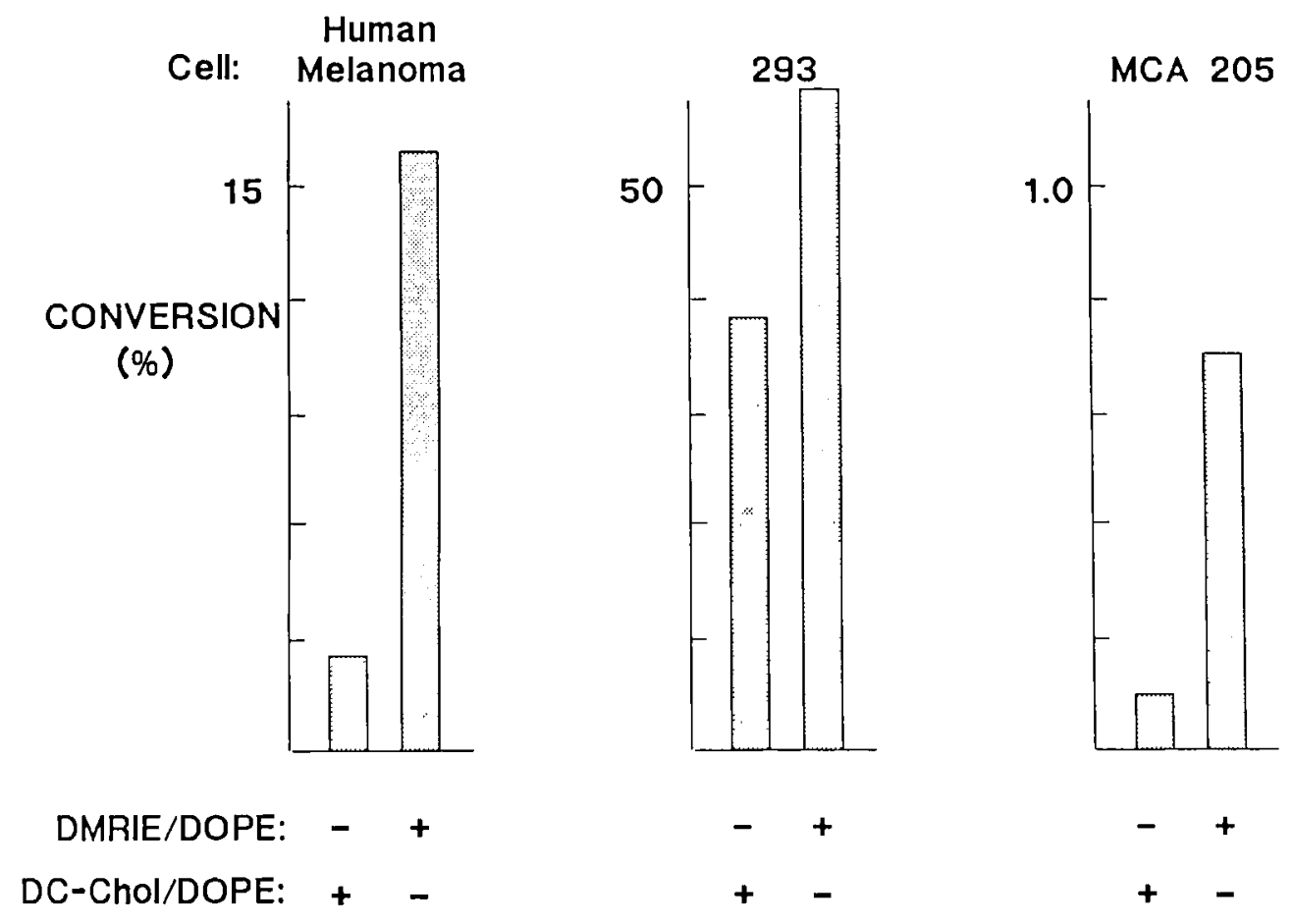

FIG. 1. Improved transfection efficiency of DMRIE/DOPE DNA-liposome complex. Cells were incubated with DNA-liposomes reconstituted in Ringer's lactate solution for $1.5 \mathrm{hr}$ and analyzed after $36 \mathrm{hr}$. Transfection efficiencies of DMRIE/DOPE and DC-Chol/DOPE are shown. Percent transfected cells were analyzed by X-gal staining (Nabel et al., 1989). Standard deviations were $<10 \%$. 

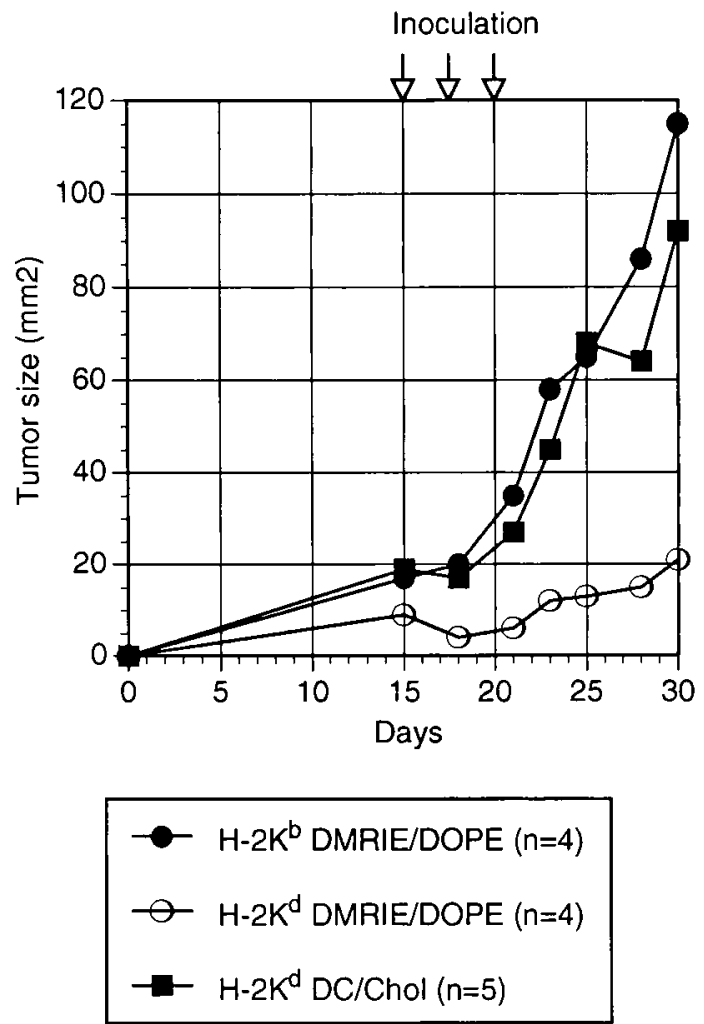

FIG. 2. Improved antitumor effect with DMRIE/DOPE liposomes compared to DC-Chol/DOPE. C57/BL6 mice $\left(\mathrm{H}-2 \mathrm{~K}^{\mathrm{b}}\right)$ were inoculated with MCA 205 fibrosarcoma tumor cells subcutaneously in the left posterior hind flank on day 0 . Presensitization was performed by subcutaneous injection of $\mathrm{BALB} / \mathrm{c}$ $\left(\mathrm{H}-2 \mathrm{~K}^{\mathrm{d}}\right)$ spleen cells, $5 \times 10^{6}$ on day -6 , and $2 \times 10^{6}$ on day +1 . Tumors were injected $(0.1 \mathrm{ml}$ total volume $)$ on days 15 , 18 , and 20 with: (i) CMV H-2K $5 \mu \mathrm{g}$ and DMRIE/DOPE 15 nmol (-๑); (ii) CMV H-2Kd $5 \mu \mathrm{g}$ and DMRIE/DOPE $15 \mathrm{nmol}$ (-); and (iii) CMV H-2K $5 \mu \mathrm{g}$ and DC/Chol/DOPE $15 \mathrm{nmol}$ $(--)$. Tumor size, calculated as the product of two perpendicular diameters, was measured at the indicated times. Standard deviations for each point were $<20 \%$.
DOPE formulation, a marked antitumor effect was obtained after introduction of a foreign MHC gene $\left(\mathbf{H}-2 \mathrm{~K}^{\mathrm{d}}\right)$ that was not seen with DC-Chol (Fig. 2).

\section{Distribution of DNA-liposome complexes after intravenous and intra-arterial administration}

To characterize the distribution of DNA-liposome complexes after injection in vivo, the complexes were prepared and injected into the tail vein of BALB/c mice. The RSV HLA-B7 plasmid used for the human gene therapy protocol was utilized for these studies. Increasing concentrations of DNA-liposome complexes were tested in three groups. The lowest dose represented a 10 -fold higher initial dose than for the human gene therapy trial $(0.5 \mu \mathrm{g}$ plasmid DNA; $1.5 \mathrm{nmol}$ DMRIE/DOPE) based on a weight/body surface area ratio. The highest dose was 1,000-fold greater. PCR analysis of DNA from major murine organs, including heart, lung, brain, liver, and kidney, showed that the injected DNA was detected in multiple organs, including the lung and heart, with these mice after 10 days (Table 1A). However, the presence of DNA in these organs was not associated with organ pathology (see below). The localization of DNA-liposome complexes in different tissues has been described previously (Stewart et al., 1992), where it was found transiently in cells of the reticuloendothelial cell system.

Localized gene transfer to arterial segments was performed in 12 pigs at three doses, HLA-B7 DNA $0.5 \mu \mathrm{g}$ and DMRIE/ DOPE $1.5 \mathrm{nmol}$ (2 pigs), HLA-B7 DNA $5.0 \mu \mathrm{g}$ and DMRIE/ DOPE $15 \mathrm{nmol}$ (4 pigs), and HLA-B7 DNA $50 \mu \mathrm{g}$ and DMRIE/ DOPE $150 \mathrm{nmol}$ (6 pigs). The right and left iliofemoral arteries were transfected in the 12 pigs, for a total of 24 arteries. PCR analysis from these pigs demonstrated HLA-B7 DNA in 20 of 24 arteries, 3 of 4 arteries transfected at the $0.5 \mu \mathrm{g} / 1.5 \mathrm{nmol}$ dose, 6 of 8 arteries transfected at the $5.0 \mu \mathrm{g} / 15 \mathrm{nmol}$ dose, and 11 of 12 arteries transfected at the $50 \mu \mathrm{g} / 150 \mathrm{nmol}$ dose. In addition, PCR analysis did not demonstrate HLA-B7 DNA in major organs 17 days following intraarterial gene transfer (Table 1B).

Table 1. Localization of Recombinant Genes by PCR after Introduction In Vivo in Mice and PIgS

\begin{tabular}{lcccccccc}
\hline A. DNA/liposome & Brain & Heart & Lung & Liver & Kidney & Spleen & Muscle & Ovary \\
\hline $0.5 \mu \mathrm{g} / 1.5 \mathrm{nmol}$ & $2 / 6$ & $5 / 6$ & $5 / 6$ & $2 / 6$ & $3 / 6$ & $2 / 6$ & $0 / 6$ & $0 / 6$ \\
$5.0 \mu \mathrm{g} / 15 \mathrm{nmol}$ & $2 / 6$ & $1 / 6$ & $2 / 6$ & $3 / 6$ & $2 / 6$ & $4 / 6$ & $0 / 6$ & $0 / 6$ \\
$50 \mu \mathrm{g} / 150 \mathrm{nmol}$ & $0 / 3$ & $0 / 3$ & $0 / 3$ & $0 / 3$ & $0 / 3$ & $0 / 3$ & $0 / 3$ & $0 / 3$ \\
\hline
\end{tabular}

Mice were injected with $0.1 \mathrm{ml}$ of the indicated concentrations of HLA-B7 plasmid and DMRIE/DOPE, and DNA was extracted from the indicated tissues at 10 days for analysis by PCR. Mice received injections by tail vein. The number of animals which tested positive relative to the total number analyzed is indicated.

\begin{tabular}{|c|c|c|c|c|c|c|c|c|}
\hline B. DNA/liposome & Heart & Lung & Liver & Kidney & Spleen & Muscle & $\begin{array}{c}\text { Nontransfected } \\
\text { artery }\end{array}$ & Ovary \\
\hline $0.5 \mu \mathrm{g} / 1.5 \mathrm{nmol}$ & $0 / 2$ & $0 / 2$ & $0 / 2$ & $0 / 2$ & $0 / 2$ & $0 / 2$ & $0 / 2$ & $0 / 2$ \\
\hline $5.0 \mu \mathrm{g} / 15 \mathrm{nmol}$ & $0 / 2$ & $0 / 2$ & $0 / 2$ & $0 / 2$ & $0 / 2$ & $0 / 2$ & $0 / 2$ & $0 / 2$ \\
\hline $50 \mu \mathrm{g} / 150 \mathrm{nmol}$ & $0 / 3$ & $0 / 3$ & $0 / 3$ & $0 / 3$ & $0 / 3$ & $0 / 3$ & $0 / 3$ & $0 / 3$ \\
\hline
\end{tabular}

Pigs were treated with indicated concentrations of plasmid DNA and DMRIE/DOPE by arterial gene transfer (Nabel et al., 1993a,b). DNA was extracted from the indicated tissues at 17 days and analyzed as in A. 
Table 2. Evaluation of Selected Serum Enzymes and Chemistries Before and After a Single InTravenous INJECTION OF HLA-B7 DNA-LIPOSOMES IN MICE

\begin{tabular}{|c|c|c|c|c|c|c|}
\hline \multirow[t]{2}{*}{$\begin{array}{l}\text { Plasmid }(\mu g) \text { : } \\
\text { DMRIE/DOPE (nmol): }\end{array}$} & \multicolumn{2}{|c|}{$\begin{array}{l}0.5 \\
1.5\end{array}$} & \multicolumn{2}{|c|}{$\begin{array}{r}5 \\
15\end{array}$} & \multicolumn{2}{|c|}{$\begin{array}{r}50 \\
150\end{array}$} \\
\hline & Pre & Post & Pre & Post & Pre & Post \\
\hline Albumin $(\mathrm{g} / \mathrm{dl})$ & $3.4 \pm 0.4$ & $3.3 \pm 0.3$ & $3.3 \pm 0.4$ & $3.2 \pm 0.3$ & $3.1 \pm 0 . \mathrm{I}$ & $3.3 \pm 0.2$ \\
\hline Alk Phos (IU/liter) & $146 \pm 21$ & $152 \pm 13$ & $164 \pm 14$ & $170 \pm 17$ & $172 \pm 8$ & $193 \pm 23$ \\
\hline Amylase (U/liter) & $2,261 \pm 31$ & $2,337 \pm 192$ & $2,395 \pm 277$ & $2,465 \pm 339$ & $2,6 \mathrm{I} 2 \pm 166$ & $2,226 \pm 217$ \\
\hline Bilirubin (mg/dl) & $0.1 \pm 0$ & $0.1 \pm 0$ & $0.1 \pm 0$ & $0.1 \pm 0$ & $0.1 \pm 0.1$ & $0.1 \pm 0$ \\
\hline BUN (mg/dl) & $20 \pm 4$ & $25 \pm 2$ & $35 \pm 6$ & $26 \pm 3$ & $24 \pm 9$ & $20 \pm 0$ \\
\hline Creatinine (mg/dl) & $0.5 \pm 0.2$ & $0.6 \pm 0.3$ & $0.5 \pm 0.2$ & $0.3 \pm 0$ & $1.0 \pm 0.2$ & $0.2 \pm 0$ \\
\hline SGOT (IU/liter) & $71 \pm 8$ & $60 \pm 7$ & $57 \pm 3$ & $61 \pm 6$ & $40 \pm 12$ & $60 \pm 8$ \\
\hline Total protein $(\mathrm{g} / \mathrm{dl})$ & $6.3 \pm 0.8$ & $5.2 \pm 0.2$ & $5.4 \pm 0.8$ & $5.4 \pm 0.6$ & $5.0 \pm 0$ & $4.5 \pm 0.2$ \\
\hline
\end{tabular}

Blood samples were obtained from BALB/c female mice $(n=5)$ prior to intravenous injection (Pre) and 10 days after (Post) tail vein injection with the indicated concentrations of DNA-Iiposome complexes. Serum enzyme and chemistry values were analyzed (Roche Biomedical Laboratory), and mean values and standard deviations are shown.

\section{Organ toxicity}

To determine whether the introduction of DNA-liposome complexes in vivo produced toxicity to major organ systems, several serum biochemical parameters were evaluated either after a single injection or after three separate injections made at 2 -week intervals in mice and pigs. The previous studies regarding the long-term toxicity and immunologic consequences of expression of a foreign MHC gene have been previously reported with no adverse effects noted (E.G. Nabel et al., 1992a). Analysis of serum enzymes and protein from liver, kidney, bone, and pancreas revealed no significant changes 10 days after a single injection (Table 2) or 14 days after three treatments administered at 2-week intervals (Table 3 ). Similar analyses were performed in pigs that received arterial gene transfer with DNA-liposome complexes, and no biochemical abnormalities were observed (Table 4). Pathology analysis of tissues from these animals showed occasional incidental changes unrelated to the introduction of DNA-liposome complexes (Table 5). The incidental findings, including occasional peribronchial lymphoid aggregates in the lung or liver were seen in control animals that did not receive DNA-liposome treatments in previous studies (E.G. Nabel et al., 1992a; Stewart et al., 1992). Similarly, no pathological abnormalities were detected after three treatments with DNA-liposome complexes in mice (data not shown), analogous to the protocol used in our human clinical trial (G.J. Nabel et al., 1992a, 1993). In addition, toxicity studies were performed in pigs following direct arterial gene transfer. These pathology studies demonstrated that the administration of DNA-liposome complexes intra-arterially was welltolerated in vivo, with no adverse responses detected biochemically (Table 4) or in tissues (Table 5).

\section{Cardiac toxicity}

As in previous studies, plasmid DNA was detected after intravenous injection in the heart by PCR analysis. Therefore, we examined whether this formulation caused significant acute or chronic toxicity from this treatment. We first evaluated the

Table 3. Evaluation of Selected Serum Enzymes and Chemistries Before and After Three Intravenous INJECTIONS OF HLA-B7 DNA-LIPOSOME COMPLEXES IN MICE

\begin{tabular}{|c|c|c|c|c|c|c|}
\hline \multirow[t]{2}{*}{$\begin{array}{l}\text { Plasmid }(\mu \mathrm{g}) \text { : } \\
\text { DMRIE/DOPE (nmol): }\end{array}$} & \multicolumn{2}{|c|}{$\begin{array}{l}0.5 \\
1.5\end{array}$} & \multicolumn{2}{|c|}{$\begin{array}{r}5 \\
15\end{array}$} & \multicolumn{2}{|c|}{$\begin{array}{r}50 \\
150\end{array}$} \\
\hline & Pre & Post & Pre & Post & Pre & Post \\
\hline Albumin $(g / d l)$ & $3.4 \pm 0$ & $2.9 \pm 0$ & $3.1 \pm 0.2$ & $2.9 \pm 0$ & $3.2 \pm 0.1$ & $3.2 \pm 0.2$ \\
\hline Alk Phos (IU/liter) & $152 \pm 8$ & $113 \pm 10$ & $161 \pm 16$ & $124 \pm 14$ & $170 \pm 8$ & $182 \pm 11$ \\
\hline Amylase (U/liter) & $2,246 \pm 17$ & $2,319 \pm 185$ & $2,213 \pm 172$ & $2,223 \pm 116$ & $2,585 \pm 178$ & $2,183 \pm 277$ \\
\hline Bilirubin (mg/dl) & $0.1 \pm 0$ & $0.1 \pm 0$ & $0.1 \pm 0$ & $0.1 \pm 0$ & $0.1 \pm 0$ & $0.3 \pm 0$ \\
\hline BUN (mg/dl) & $21 \pm 3$ & $18 \pm 3$ & $37 \pm 7$ & $23 \pm 8$ & $26 \pm 10$ & $22 \pm 3$ \\
\hline Creatinine (mg/dl) & $0.7 \pm 0$ & $0.4 \pm 0.3$ & $0.4 \pm 0.3$ & $0.4 \pm 0.3$ & $1 \pm 0$ & $0.3 \pm 0$ \\
\hline Phosphorous (mg/dl) & $6.7 \pm 0.5$ & $6.2 \pm 0.5$ & $7.2 \pm 0.5$ & $5 \pm 0.8$ & $7.6 \pm 0.9$ & $7.7 \pm 1.8$ \\
\hline SGOT (IU/liter) & $69 \pm 10$ & $53 \pm 15$ & $56 \pm 3$ & $69 \pm 28$ & $41 \pm 13$ & $46 \pm 2$ \\
\hline SGPT (IU/liter) & $35 \pm 3$ & $27 \pm 9$ & $31 \pm 8$ & $37 \pm 5$ & $25 \pm 4$ & $26 \pm 2$ \\
\hline Total protein $(\mathrm{g} / \mathrm{dl})$ & $6.3 \pm 1$ & $4.8 \pm 0.3$ & $5.4 \pm 0.9$ & $5.1 \pm 0.5$ & $5.0 \pm 0$ & $4.8 \pm 0$ \\
\hline
\end{tabular}

Blood samples were obtained from BALB/c female mice $(n=5)$ prior to intravenous injection (Pre) and 14 days after (Post) the third injection of DNA-liposome complexes at the indicated concentrations. Serum enzyme and chemistry values were analyzed (Roche Biomedical Laboratory), and mean values and standard deviations are shown. 
Table 4. Evaluation of Selected Serum Enzymes and Chemistries Before and After Arterial Gene Transfer OF HLA-B7 DNA-LiPOSOME COMPLEXES IN PIGS

\begin{tabular}{|c|c|c|c|c|}
\hline \multirow[t]{2}{*}{$\begin{array}{l}\text { Plasmid }(\mu \mathrm{g}) \text { : } \\
\text { DMRIE } / D O P E(n m o l):\end{array}$} & \multicolumn{2}{|c|}{$\begin{array}{r}5 \\
15\end{array}$} & \multicolumn{2}{|c|}{$\begin{array}{r}50 \\
150 \\
\end{array}$} \\
\hline & Pre & Post & Pre & Post \\
\hline Albumin $(\mathrm{g} / \mathrm{dl})$ & $3.2 \pm 0.4$ & $3.2 \pm 0.2$ & $3.3 \pm 0.3$ & $3.4 \pm 0.3$ \\
\hline Alk Phos (IU/liter) & $298 \pm 62$ & $186 \pm 29$ & $241 \pm 97$ & $206 \pm 51$ \\
\hline Amylase (U/liter) & $1,799 \pm 139$ & $2,170 \pm 470$ & $2,269 \pm 605$ & $2,527 \pm 1,297$ \\
\hline Bilirubin (mg/dl) & $0.14 \pm 0.05$ & $0.22 \pm 0.04$ & $0.10 \pm 0$ & $0.14 \pm 0.05$ \\
\hline BUN (mg/dl) & $8 \pm 3$ & $9 \pm 3$ & $6 \pm 1$ & $10 \pm 2$ \\
\hline Calcium (mg/dl) & $9.3 \pm 0.2$ & $9.3 \pm 0.4$ & $9.5 \pm 0.6$ & $9.5 \pm 1.0$ \\
\hline Chloride (mEq/liter) & $101 \pm 1$ & $99 \pm 5$ & $103 \pm 1$ & $101 \pm 5$ \\
\hline Creatinine $(\mathrm{mg} / \mathrm{dl})$ & $0.9 \pm 0.1$ & $1.1 \pm 0.1$ & $0.8 \pm 0.1$ & $1.2 \pm 0.2$ \\
\hline Glucose $(\mathrm{mg} / \mathrm{dl})$ & $111 \pm 57$ & $134 \pm 54$ & $102 \pm 56$ & $116 \pm 22$ \\
\hline LDH (IU/liter) & $538 \pm 146$ & $507 \pm 161$ & $425 \pm 62$ & $489 \pm 173$ \\
\hline Phosphorous (mg/dl) & $10.3 \pm 0.7$ & $7.9 \pm 0.8$ & $10.5 \pm 1.4$ & $10.9 \pm 4.1$ \\
\hline Potassium (mEq/liter) & $5.1 \pm 1.0$ & $4.4 \pm 0.8$ & $4.5 \pm 0.4$ & $4.8 \pm 1.1$ \\
\hline SGOT (IU/liter) & $28 \pm 8$ & $44 \pm 30$ & $27 \pm 13$ & $43 \pm 30$ \\
\hline SGPT (IU/liter) & $29 \pm 14$ & $42 \pm 12$ & $36 \pm 9$ & $40 \pm 7$ \\
\hline Sodium (mEq/liter) & $139 \pm 2$ & $135 \pm 5$ & $143 \pm 2$ & $142 \pm 9$ \\
\hline Total protein $(\mathrm{g} / \mathrm{dl})$ & $5.0 \pm 0.1$ & $5.4 \pm 0.5$ & $5.7 \pm 0.5$ & $5.7 \pm 0.5$ \\
\hline
\end{tabular}

Blood samples were obtained from pigs $(n=10)$ prior to (Pre) and 17 days after (Post) arterial gene transfer of DNA-liposome complexes at the indicated concentrations ( $n=5$ for each concentration). Serum enzyme and chemistry values were analyzed (Roche Biomedical Laboratory), and mean values and standard errors of the mean are shown. All values fall within the range of normal limits (Nabel et al.. I992a),

potential for acute effects of this treatment by examining the electrocardiogram before, during, and after injection on DMRIE/DOPE plasmid complexes. As observed with DC-Chol liposomes, this analysis revealed no abnormalities in rate or rhythm after intravenous injection (Fig. 3). As a further evaluation of cardiac toxicity, CPK measurements were performed in mice before or after injection with DNA-liposome complexes. No significant changes in CPK levels were noted pre- or postinjection (Table 6). In addition to these analyses, histopathological analysis of tissue was performed. No significant pathologi- cal abnormalities were detected at 14 days to 6 weeks after injection (Table 5). In summary, despite the detection of complexes by PCR within the myocardium, there was no acute or chronic cardiac toxicity from this treatment.

\section{DISCUSSION}

The potential of nonviral vectors as a delivery vehicle for human gene therapy has expanded over the past several years.

Table 5. Histological analysis of Tissue Following Introduction of DNA-Liposomes In Vivo

\begin{tabular}{|c|c|c|c|c|c|}
\hline \multirow{2}{*}{$\begin{array}{l}\text { Species: } \\
\mu \mathrm{g} \text { DNA/nmol liposome: }\end{array}$} & \multicolumn{3}{|c|}{ Mice } & \multicolumn{2}{|c|}{ Pigs } \\
\hline & $\begin{array}{l}0.5 / 1.5 \\
(\mathrm{n}=5)\end{array}$ & $\begin{array}{c}5 / 15 \\
(n=5)\end{array}$ & $\begin{array}{c}50 / 150 \\
(\mathrm{n}=14)\end{array}$ & $\begin{array}{c}5 / 15 \\
(n=4)\end{array}$ & $\begin{array}{l}50 / 150 \\
(\mathrm{n}=6)\end{array}$ \\
\hline Heart & Normal & Normal & Normal & Normal & Normal \\
\hline \multicolumn{6}{|l|}{ Lung } \\
\hline $\begin{array}{l}{ }^{\mathrm{a}} \text { Focal peribronchial } \\
\text { lymphoid aggregates }\end{array}$ & $2 / 5$ & Normal & $3 / 14$ & $3 / 4$ & $3 / 6$ \\
\hline \multicolumn{6}{|l|}{ Liver } \\
\hline $\begin{array}{l}{ }^{\mathrm{a}} \text { Focal portal mononuclear } \\
\text { inflammatory aggregates }\end{array}$ & $2 / 5$ & $2 / 5$ & $4 / 14$ & Normal & $3 / 6$ \\
\hline \multicolumn{6}{|l|}{ Kidney } \\
\hline $\begin{array}{l}{ }^{a} \text { Focal interstitial } \\
\text { mononuclear inflammatory cells }\end{array}$ & Normal & Normal & $1 / 14$ & Normal & Normal \\
\hline Spleen & Normal & Normal & Normal & Normal & Normal \\
\hline Skeletal muscle & Normal & Normal & Normal & Normal & Normal \\
\hline Nontransfected artery & ND & ND & ND & Normal & Normal \\
\hline Ovary & Normal & Normal & Normal & Normal & Normal \\
\hline
\end{tabular}

ND, not determined.

${ }^{a}$ Minor pathologic changes of no clinical significance. 

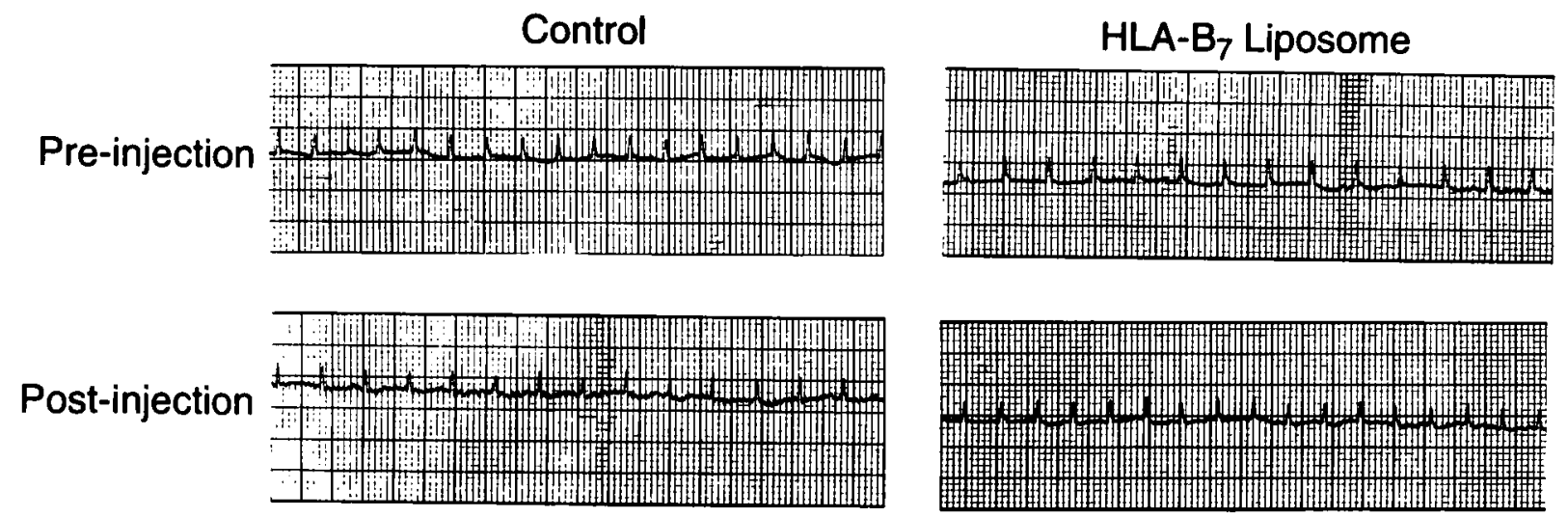

FIG. 3. Effect of DNA-liposome infusions on cardiac rate and rhythm measured by electrocardiography. Five mice were monitored electrocardiographically before and after intravenous infusions of saline (control, $n=2)$ or HLA-B7 liposomes $(n=3)$. Female BALB/c mice were anesthetized by metathane inhalation. Surface electrodes were attached to the four limbs, and surface lead I or II was recorded continuously at $50 \mathrm{~mm} / \mathrm{sec}$ paper speed. Representative tracings are shown for each group pre-injection and 5 min post-injection.

In theory, a variety of such vectors could be employed for gene transfer in vivo, including DNA-liposome complexes, naked plasmid DNA, protein/DNA, or inactivated viral DNA complexes. In this study, we examine the toxicities of a novel DNA-liposome complex that may provide for a substantial increase in the amount of recombinant DNA which could be administered in vivo. In this formulation, the cationic lipid, DMRIE, has been substituted for DC-Chol. The resulting DNA-liposome complex has enhanced transfection efficiencies in vitro (Fig. 1). Although the magnitude of this effect is relatively small (two- to seven-fold), these plasmids do not aggregate at higher cell concentrations, and a substantially higher quantity of plasmid can be introduced in vivo by this method. This DNA-liposome also has the ability to facilitate an antitumor response in a case where the other liposome is less active (Fig. 2).

The ability to introduce genes at higher concentrations could enhance gene transfer and stimulate increased synthesis of gene products that are required for therapeutic effects. For example, recently, high-level concentrations of Lipofectin (BRL, Gaithersburg, MD) and plasmid expression vectors have been described that allow for gene expression systemically following intravenous infection (Zhu et al., 1993). Additional Phase 1 studies will be required in humans to test this possibility. This

TaBle 6. Measurements of Total CPK (U/L) BEFORE AND AFTER INTRAVENOUS INJECTION WITH DNA-LIPOSOMES IN MICE

\begin{tabular}{lccc}
\hline Plasmid $(\mu \mathrm{g}):$ & 0.5 & 5 & 50 \\
DMRIE/DOPE $(\mathrm{nmol}):$ & 1.5 & 15 & 150 \\
\hline Pre-injection & $339 \pm 122$ & $156 \pm 44$ & $156 \pm 44$ \\
Post-injection & $189 \pm 63$ & $163 \pm 44$ & $163 \pm 44$ \\
& $p \leqslant 0.79$ & $p \leqslant 0.96$ & $p \leqslant 0.31$ \\
\hline
\end{tabular}

Serum samples were obtained from $B A L B / c$ female mice prior to intravenous injection and $16 \mathrm{hr}$ following injection of HLA-B7 liposome complexes ( $n=5$, each dose). Serum was analyzed by Roche Biomedical Laboratory (Burlington, NC). study, together with previous studies that have demonstrated the relative safety of other DNA-liposome complexes (Nabel et al., 1992a; Stewart et al., 1992), provides evidence that the administration of such compounds in vivo is well tolerated.

The present study confirms that this treatment is tolerated at doses up to 1,000-fold higher than previously analyzed and has the potential to deliver larger quantities of genes. As in previous studies, although DNA was detected in the myocardium following intravenous injection, there was no effect on myocardial function, either acutely or chronically. Therefore, the intravenous infusion of DNA-liposome complexes continues to appear safe with regard to cardiac function even at higher doses. Finally, the concern was raised regarding the potential for inadvertent introduction of DNA into germ cells. We found that DNA was not detected in gonadal tissue, following gene transfer with DNA/DC-Chol complexes, even by PCR (Nabel et al., 1992a). The previous study used lower doses of the DNAliposome complex. The present study also confirms that the lack of recombinant DNA in gonadal tissue at concentrations up to 1,000-fold greater than those reported previously. Taken together, these data suggest that several cationic lipids may be useful for human gene therapy and are unlikely to cause significant toxicity at these doses, even when modifications are made in one of the charged lipid components. These data also suggest that additional modifications of the lipid can be incorporated in the future that will facilitate the efficiency of targeting DNAliposome complexes to specific tissues in vivo.

\section{REFERENCES}

FELGNER, J.H., KUMAR, R., SRIDHAR, C.N., WHEELER, C.J., TSAI, Y.J., BORDER, R., RAMSEY, P., MARTIN, M., and FELGNER, P.L. (1993). Enhanced gene delivery and mechanism studies with a novel series of cationic lipid formulations-part I. J. Biol. Chem. (in press).

GAO, X., and HUANG, L. (1991). A novel cationic liposome reagent for efficient transfection of mammalian cells. Biochem. Biophys. Res. Commu. 179, 280-285. 
NABEL, E.G., PLAUTZ. G., BOYCE, F.M., STANLEY, J.C., and NABEL. G.J. (1989). Recombinant gene expression in vivo within endothelial cells of the arterial wall. Science 244, 1342-1344.

NABEL, E.G., PLAUTZ, G., and NABEL. G.J. (1990). Site-specific gene expression in vivo by direct gene transfer into the arterial wall. Science 249, 1285-1288.

NABEL, E.G., GORDON, D., YANG, Z-Y., XU, L., SAN, H., PLAUTZ, G.E., WU, B-Y., GAO, X., HUANG, L., and NABEL, G.J. (1992a). Gene transfer in vivo with DNA-liposome complexes: lack of autoimmunity and gonadal localization. Hum. Gene Ther. 3, 649-656.

NABEL, E.G.. PLAUTZ. G., and NABEL. G.J. (1992b). Transduction of a foreign histocompatibility gene into the arterial wall induces vasculitis. Proc, Natl. Acad. Sci. USA 89, 5157-5161.

NABEL, E.G., YANG, Z., LIPTAY, S., SAN, H., GORDON, D. HAUDENSCHILD, C.C., and NABEL, G.J. (1993a). Recombinant platelet-derived growth factor $\mathrm{B}$ gene expression in porcine arteries induces intimal hyperplasia in vivo. J. Clin. Invest. 91, 1822-1829.

NABEL, E.G., YANG, Z.Y, PLAUTZ, G., FOROUGH, R., ZHAN, X., HAUDENSCHILD, C.C., MACIAG, T., and NABEL, G.J. (1993b). Recombinant fibroblast growth factor-1 gene expression promotes intimal hyperplasia and angiogenesis in arteries in vivo. Nature 362, 844-846.

NABEL, G.J., CHANG, A., NABEL, E.G., PlAUTZ, G., FOX, B.A., HUANG, L., and SHU, S. (1992a). Clinical Protocol: Immunotherapy of malignancy by in vivo gene transfer into tumors. Hum. Gene Ther. 3, 399-410.

NABEL, G.J., CHANG, A., NABEL, E.G., PLAUTZ, G., FOX, B.A., HUANG, L., and SHU, S. (1992b). Clinical Protocol: Response to the points to consider for immunotherapy of malignancy by in vivo gene transfer into tumors. Hum. Gene Ther. 3, 705-711.
NABEL, G.J., NABEL, E.G., YANG, Z.-Y., FOX, B.A., PLAUTZ, G.E., GAO, X., HUANG, L., SHU, S., GORDON, D., and CHANG, A.E. (1993). Direct gene transfer with DNA liposome complexes in melanoma: Expression, biologic activity and lack of toxicity in humans. Proc. Natl. Acad. Sci. USA (in press).

PLAUTZ, G.E., YANG, Z., WU, B., GAO, X., HUANG, L., and NABEL, G.J. (1993). Immunotherapy of malignancy by in vivo gene transfer into tumors. Proc. Natl. Acad. Sci. USA 90, 46454649.

STEWART, M.J., PLAUTZ, G.E., DEL BUONO, L., YANG, Z.Y., XU, L., GAO, X., HUANG, L., NABEL, E.G., and NABEL, G.J. (1992). Gene transfer in vivo with DNA-liposome complexes: safety and acute toxicity in mice. Hum. Gene Ther. 3, 267-275.

ZHU, N., LIGGITT, D., LIU, Y., and DEBS, R. (1993). Systemic gene expression after intravenous DNA delivery into adult mice. Science 261, 209-211.

Address reprint requests to:

Dr. Gary Nabel

Howard Hughes Medical Institute

Departments of Internal Medicine and Biological Chemistry University of Michigan Medical Center II50 W. Medical Center Drive 4510 MSRBI

Ann Arbor, MI 48109-0650

Received for publication June 16, 1993; accepted after revision August 16, 1993. 
This article has been cited by:

1. Adrián Vilalta, Gretchen Jimenez, Denis Rusalov, Rodrick Planchon, Peggy Lalor, Kristin Carner, Jennifer A. Chaplin , Michael Komai , Marston Manthorpe , David C. Kaslow , Alain Rolland . 2007. Vaccination with Polymerase Chain Reaction-Generated Linear Expression Cassettes Protects Mice Against Lethal Influenza A ChallengeVaccination with Polymerase Chain Reaction-Generated Linear Expression Cassettes Protects Mice Against Lethal Influenza A Challenge. Human Gene Therapy 18:8, 763-771. [Abstract] [PDF] [PDF Plus]

2. Jeffrey A. Gruneich, Scott L. Diamond. 2007. Synthesis and structure-activity relationships of a series of increasingly hydrophobic cationic steroid lipofection reagents. The Journal of Gene Medicine 9:5, 381-391. [CrossRef]

3. Adrian Vilalta, Rohit K. Mahajan, Jukka Hartikka, Vicky Leamy, Terrie Martin, Denis Rusalov, Vesselina Bozoukova, Peggy Lalor, Keith Hall, David C. Kaslow, Alain Rolland. 2005. II. Cationic Lipid-Formulated Plasmid DNA-Based Bacillus anthracis Vaccine: Evaluation of Plasmid DNA Persistence and Integration Potential. Human Gene Therapy, ahead of print050921070028001. [CrossRef]

4. Adrian Vilalta, Rohit K. Mahajan, Jukka Hartikka, Vicky Leamy, Terrie Martin, Denis Rusalov, Vesselina Bozoukova, Peggy Lalor, Keith Hall, David C. Kaslow, Alain Rolland. 2005. II. Cationic Lipid-Formulated Plasmid DNA-Based Bacillus anthracis Vaccine: Evaluation of Plasmid DNA Persistence and Integration Potential. Human Gene Therapy, ahead of print050912085138001. [CrossRef]

5. Dr. Adrián Vilalta, Rohit K. Mahajan , Jukka Hartikka, Vicky Leamy, Terrie Martin , Denis Rusalov, Vesselina Bozoukova, Peggy Lalor, Keith Hall , David C. Kaslow, Alain Rolland . 2005. II. Cationic Lipid-Formulated Plasmid DNA-Based Bacillus anthracis Vaccine: Evaluation of Plasmid DNA Persistence and Integration PotentialII. Cationic Lipid-Formulated Plasmid DNA-Based Bacillus anthracis Vaccine: Evaluation of Plasmid DNA Persistence and Integration Potential. Human Gene Therapy 16:10, 1151-1156. [Abstract] [PDF] [PDF Plus]

6. Thomas K. Han, My Lien Dao . 2005. Differential Immunogenicity of a DNA Vaccine Containing the Streptococcus mutans Wall-Associated Protein A Gene Versus That Containing a Truncated Derivative Antigen A Lacking in the Hydrophobic Carboxyterminal RegionDifferential Immunogenicity of a DNA Vaccine Containing the Streptococcus mutans Wall-Associated Protein A Gene Versus That Containing a Truncated Derivative Antigen A Lacking in the Hydrophobic Carboxyterminal Region. DNA and Cell Biology 24:9, 574-581. [Abstract] [PDF] [PDF Plus]

7. Naoki Ohmiya, Nobuhiko Emi, Yasumasa Niwa, Hidemi Goto, Tetsuo Hayakawa. 2002. Insulin-Enhanced Liposome-Mediated Gene Transfer Into A Gastric Carcinoma Cell Line. Clinical and Experimental Pharmacology and Physiology 29:7, 544-548. [CrossRef]

8. Qing Zeng, Peter M. Kanter, Rajiv Dhir, William E. Gooding, Leaf Huang, Jennifer Rubin Grandis. 2002. Lack of toxicity of EGFR antisense gene therapy. Journal of Experimental Therapeutics and Oncology 2:3, 174-186. [CrossRef]

9. Masafumi Seki , Jun Iwakawa, Helen Cheng , Pi-Wan Cheng . 2002. p53 and PTEN/MMAC1/TEP1 Gene Therapy of Human Prostate PC-3 Carcinoma Xenograft, Using Transferrin-Facilitated Lipofection Gene Delivery Strategyp53 and PTEN/MMAC1/TEP1 Gene Therapy of Human Prostate PC-3 Carcinoma Xenograft, Using Transferrin-Facilitated Lipofection Gene Delivery Strategy. Human Gene Therapy 13:6, 761-773. [Abstract] [PDF] [PDF Plus]

10. Lorena Baccaglini, A. T. M. Shamsul Hoque, Robert B. Wellner, Corinne M. Goldsmith, Robert S. Redman, Vidya Sankar, Albert Kingman, Kerry M. Barnhart, Carl J. Wheeler, Bruce J. Baum. 2001. Cationic liposome-mediated gene transfer to rat salivary epithelial cellsin vitro andin vivo. The Journal of Gene Medicine 3:1, 82-90. [CrossRef]

11. Jennifer D. Tousignant, Amy L. Gates, Laurie A. Ingram, Carrie L. Johnson, Jennifer B. Nietupski, Seng H. Cheng, Simon J. Eastman, Ronald K. Scheule . 2000. Comprehensive Analysis of the Acute Toxicities Induced by Systemic Administration of Cationic Lipid:Plasmid DNA Complexes in MiceComprehensive Analysis of the Acute Toxicities Induced by Systemic Administration of Cationic Lipid:Plasmid DNA Complexes in Mice. Human Gene Therapy 11:18, 2493-2513. [Abstract] [PDF] [PDF Plus]

12. Holly M Horton, Suezanne E Parker, Mary K Wloch, Jon A Norman. 2000. DNA vaccines for cancer therapy. Expert Opinion on Investigational Drugs 8:12, 2017-2026. [CrossRef]

13. Suezanne E. Parker, Flavia Borellini, Martin L. Wenk, Peter Hobart, Stephen L. Hoffman, Richard Hedstrom, Thong Le , Jon A. Norman . 1999. Plasmid DNA Malaria Vaccine: Tissue Distribution and Safety Studies in Mice and RabbitsPlasmid DNA Malaria Vaccine: Tissue Distribution and Safety Studies in Mice and Rabbits. Human Gene Therapy 10:5, 741-758. [Abstract] [PDF] [PDF Plus] 
14. Nikolai G. Rainov, Keiro Ikeda, Nazir H. Qureshi, Shivani Grover, Ulrich Herrlinger, Peter Pechan, E. Antonio Chiocca, Xandra O. Breakefield, Faith H. Barnett . 1999. Intraarterial Delivery of Adenovirus Vectors and Liposome-DNA Complexes to Experimental Brain NeoplasmsIntraarterial Delivery of Adenovirus Vectors and Liposome-DNA Complexes to Experimental Brain Neoplasms. Human Gene Therapy 10:2, 311-318. [Abstract] [PDF] [PDF Plus]

15. Gerardo Byk, Daniel Scherman. 1998. Novel cationic lipids for gene delivery and gene therapy. Expert Opinion on Therapeutic Patents 8:9, 1125-1141. [CrossRef]

16. Ram I. Mahato, Khursheed Anwer, Frank Tagliaferri, Clare Meaney, Pat Leonard, Manpreet S. Wadhwa, Mark Logan, Martha French, Alain Rolland. 1998. Biodistribution and Gene Expression of Lipid/Plasmid Complexes after Systemic AdministrationBiodistribution and Gene Expression of Lipid/Plasmid Complexes after Systemic Administration. Human Gene Therapy 9:14, 2083-2099. [Abstract] [PDF] [PDF Plus]

17. John McC Howell, Susan Fletcher, Amanda O'Hara, Russell D. Johnsen, Frances Lloyd, Byron A. Kakulas. 1998. Direct dystrophin and reporter gene transfer into dog muscle in vivo. Muscle \& Nerve 21:2, 159-165. [CrossRef]

18. Nelson S. Yew, Donna M. Wysokenski, Kathryn X. Wang, Robin J. Ziegler, John Marshall, Dave McNeilly, Maribeth Cherry, William Osburn, Seng H. Cheng. 1997. Optimization of Plasmid Vectors for High-Level Expression in Lung Epithelial CellsOptimization of Plasmid Vectors for High-Level Expression in Lung Epithelial Cells. Human Gene Therapy 8:5, 575-584. [Abstract] [PDF] [PDF Plus]

19. Dominique J. Stephan, Zhi-Yong Yang, Hong San, Robert D. Simari, Carl J. Wheeler, Philip L. Felgner, David Gordon, Gary J. Nabel, Elizabeth G. Nabel. 1996. A New Cationic Liposome DNA Complex Enhances the Efficiency of Arterial Gene Transfer In VivoA New Cationic Liposome DNA Complex Enhances the Efficiency of Arterial Gene Transfer In Vivo. Human Gene Therapy 7:15, 1803-1812. [Abstract] [PDF] [PDF Plus]

20. Jonathan Fox. 1996. Therapeutic Drug Monitoring 18:4, 410-422. [CrossRef]

21. Hee Joong Kim, James F. Greenleaf, Randall R. Kinnick, James T. Bronk, Mark E. Bolander. 1996. Ultrasound-Mediated Transfection of Mammalian CellsUltrasound-Mediated Transfection of Mammalian Cells. Human Gene Therapy 7:11, 1339-1346. [Abstract] [PDF] [PDF Plus]

22. Wenchi Tseng, Norman B. Purvis, Frederick R. Haselton, Todd D. Giorgio. 1996. Cationic liposomal delivery of plasmid to endothelial cells measured by quantitative flow cytometry. Biotechnology and Bioengineering 50:5, 548-554. [CrossRef]

23. Lindsay A. Schwarz, Jennifer L. Johnson, Melanie Black, Seng H. Cheng, Michael E. Hogan, J. Clifford Waldrep. 1996. Delivery of DNA-Cationic Liposome Complexes by Small-Particle AerosolDelivery of DNA-Cationic Liposome Complexes by Small-Particle Aerosol. Human Gene Therapy 7:6, 731-741. [Abstract] [PDF] [PDF Plus]

24. Amy D. Ouellette, Kenneth K. Wu , Antonios G. Mikos . 1995. Cardiovascular Gene TransferCardiovascular Gene Transfer. Tissue Engineering 1:4, 311-322. [Abstract] [PDF] [PDF Plus]

25. Fred D. Ledley. 1995. Nonviral Gene Therapy: The Promise of Genes as Pharmaceutical ProductsNonviral Gene Therapy: The Promise of Genes as Pharmaceutical Products. Human Gene Therapy 6:9, 1129-1144. [Abstract] [PDF] [PDF Plus]

26. Suezanne E. Parker, H. Lee Vahlsing, Laurie M. Serfilippi, Craig L. Franklin, Soeun G. Doh, Stanislaw H. Gromkowski, Denise Lew, Marston Manthorpe, Jon Norman. 1995. Cancer Gene Therapy Using Plasmid DNA: Safety Evaluation in Rodents and Non-Human PrimatesCancer Gene Therapy Using Plasmid DNA: Safety Evaluation in Rodents and Non-Human Primates. Human Gene Therapy 6:5, 575-590. [Abstract] [PDF] [PDF Plus]

27. Matthew G. Dunckley, Tony A. Piper, George Dickson. 1995. Toward a gene therapy for duchenne muscular dystrophy. Mental Retardation and Developmental Disabilities Research Reviews 1:1, 71-78. [CrossRef]

28. Elizabeth G. Nabel, Zhiyong Yang, David Muller, Alfred E. Chang, Xiang Gao, Leaf Huang, Kyung J. Cho, Gary J. Nabel. 1994. Safety and Toxicity of Catheter Gene Delivery to the Pulmonary Vasculature in a Patient with Metastatic MelanomaSafety and Toxicity of Catheter Gene Delivery to the Pulmonary Vasculature in a Patient with Metastatic Melanoma. Human Gene Therapy 5:9, 1089-1094. [Abstract] [PDF] [PDF Plus] 